\title{
Artvin'in merkez köylerinde bazı tıbbi bitkilerin yöresel kullanımları
}

\section{Traditional uses of some medicinal plants in the central villages of Artvin}

\section{Funda ERŞEN BAK ${ }^{1}$ Kenan ÇiFCi ${ }^{2}$}

${ }^{1}$ Artvin Çoruh Üniversitesi, Orman Fakültesi, Orman Mühendisliği Bölümü, Artvin, Türkiye

${ }^{2}$ Artvin Il Tarım ve Orman Müdürlüğü, Artvin, Türkiye

\section{Eser Bilgisi / Article Info}

Araştırma makalesi / Research article DOI: 10.17474/artvinofd.782235

Sorumlu yazar / Corresponding author Funda ERŞEN BAK

e-mail: fundaersenbak@artvin.edu.tr

Geliş tarihi / Received

19.08.2020

Düzeltme tarihi / Received in revised form

07.09.2020

Kabul Tarihi / Accepted

08.09.2020

Elektronik erişim / Online available 17.09.2020

\begin{tabular}{l}
\hline Anahtar kelimeler: \\
Etnobotanik \\
Yöresel kullanım \\
Tıbbi bitkiler \\
Artvin \\
\hline Keywords: \\
Etnobotany \\
Ttraditional uses \\
Medicinal plants \\
Artvin \\
\hline
\end{tabular}

\begin{abstract}
Özet
Bu çalışma, 2016-2019 yılları arasında Artvin ili merkez ilçesine bağlı 7 mahalle ve 36 köyde toplam 138 kişi ile yüz yüze görüşmeler yapılarak gerçekleştirilmiştir. Araştırmada, Artvin ili merkez köylerinde yerleşik yaşayan halkın doğal tıbbi bitkiler hakkındaki bilgi düzeyleri, bu bitkilerin yöresel adları ve kullanılan kısımları, kullanım amaçları ve kullanma şekilleri ortaya konulmaya çalışımıştır. Demografik özellikleri de belirlenen yerel halkın, kendisine ait bitkisel herhangi bir karışımının olup olmadığı sorgulanmıştır. Yöre halkı tarafından, tıbbi amaçlarla 27 familyaya ait 43 farklı bitkinin kullanıldığı tespit edilmiştir. Tıbbi olarak en çok kullanılan türleri barındıran familyalar Rosaceae, Asteraceae, Lamiaceae olarak sıralanmıştır. Analiz edilen veriler ile tıbbi bitkilerin kullanım değeri (VU), hastalık grupları için kullanılan bitkiler hakkında bilgi verenler arasında fikir birliği olup olmadığı (FIC) ve bu bitkilerin kullanım yoğunluğu (FL) belirlenmiştir. Başta grip ve nezle olmak üzere solunum sistemi hastalıkları ve cilt hastalıklarında bitkilerle geleneksel tedavi yöntemlerinin kullanıldığı ve bu hastalıkların tıbbi bitkilerle tedavisi konusunda fikir birliğinin yüksek olduğu sonucuna varılmıştır.
\end{abstract}

\begin{abstract}
This study was carried out by making face-to-face interviews with a total of 138 people in 7 neighborhoods and 36 villages of the central district of Artvin between 2016 and 2019. In this study, the knowledge level of the local people in the research area about natural medicinal plants, the vernacular names of plants, used parts of these plants, their usage purposes, and usage methods were tried to be revealed. It was questioned whether the local people, whose demographic characteristics were also determined, had any herbal mixture of their own. It was determined that 43 different plants belonging to 27 families were used by the local people for medicinal purposes. The families that contain the most used medicinal species are listed as Rosaceae, Asteraceae, Lamiaceae. With the analyzed data, the use-value (VU) of medicinal plants, whether there is a consensus among those who gave information about the plants used for disease groups (FIC), and the use intensity (FL) of these plants were determined. It was concluded that traditional treatment methods with plants are used, especially influenza and cold, in respiratory system diseases and skin diseases, and there is a high consensus on the treatment of these diseases with medicinal plants.
\end{abstract}

\section{GiRiş}

Insanların çevresindeki mevcut bitkilerle etkileşiminin insanlık tarihi kadar eski olduğu bilinse de bilimsel olarak etnobotanik çalışmalar ancak bir asır öncesine dayanmaktadır. Etnobotanik terimi ilk kez Harshberger tarafından 1896 yılında bitkilerin yerel halk tarafından kullanımı olarak tanımlanmıştır (Heinrich 2004). Insanoğlu çok eskiden beri yaşamını sürdürebilmek, beslenmek, barınmak, şifa sağlamak gibi amaçlarla doğadan faydalanmıştır. Günümüzde, tüm dünyada insanlar çeşitli ihtiyaçlarını karşılamak amacıyla doğadan toplama yoluyla faydalandıkları doğal bitkileri veya onlardan en yararlı buldukları, istedikleri zaman ve miktarda temin edebilmek için tarımını yaptıkları, bitkileri kullanmaktadır. Gelişmekte olan ülkelerde milyonlarca insana doğadan topladıkları bitkisel ürünler önemli gelir kaynağı oluşturmaktadır.

Tıbbi bitkiler dünyada ki yerel tıbbi sistemlerin önemli bir parçası olarak özellikle kırsal alanlarda, hastalıkların tedavisinde kullanılmaya devam etmektedir (Çakılcıoğlu ve ark. 2007, Güneş ve Özhatay 2011, Hossain ve Rahman 2018, Karaköse ve ark. 2019). Dünya Sağlık Teşkilatı (WHO) dünya nüfusunun \%80'inin, Afrika nüfusunun ise \% 95'inin tıbbi bitkilere dayalı tedavi yöntemlerini kullandıklarını bildirmektedir (Ullah ve ark. 2014). Tıbbi kullanımları 
bakımından oldukça büyük bir kaynak olan çiçekli bitkilerin sadece \% 15'inin kimyasal ve farmakolojik araştırmaları yapılmıştır. Yeryüzünde yetişen tüm bitkiler düşünüldüğünde bu oran son derece düşüktür (Faydaoğlu ve Sürücüoğlu 2011, Acıbuca ve Bostan Budak 2018). Barros ve ark. (2012), geleneksel ilaçların modern ilaçların keşfi için potansiyel bilgi kaynağı olduğunu, bu ilaçların hastalıkların tedavisindeki etkinliğini doğrulayacak kimyasal ve biyolojik özellikleri ve insan sağlığına etkisi ile ilgili çalışmaların ise oldukça az olduğunu belirtmiştir.

Kültürel çeşitlilik ve zengin bitki örtüsü, zengin geleneksel tıbbın varlığının göstergesi olarak bildirilmiştir (Yeşilada 2002). Ülkemizde 3.649'u endemik olmak üzere 12 bin civarında bitki taksonu yayılış göstermektedir. Türkiye coğrafi konumu, iklim ve bitki çeşitliliği, tarımsal potansiyeli, geniş yüz ölçümü sayesinde tıbbi ve aromatik bitkiler ticaretinde önde gelen ülkelerden biridir. Türkiye florasında bitkisel drog, gıda ve katkı maddeleri, kozmetik ve parfümeri sektörlerinin girdisini oluşturan pek çok ham maddenin kaynağı çok sayıda bitki bulunmaktadır (Nohutçu ve ark. 2019). Etnobotanik araştırmalar, yerel halkın deneme yanılma yoluyla kazandığı, uzun süreçler sonunda kesinleştirdiği ve nesilden nesile aktardığı ve günümüze ulaşan çok değerli bilgilerin bilimsel olarak değerlendirilmelerini sağlar. Ülkemiz etnobotanik açıdan zengin bir mirasa sahiptir. Gelişen teknoloji, kente göç, şehirleşme gibi faktörlerin etkisi ile kırsalda yerel kullanımlar sonucunda oluşan ve şimdilerde kullanılmayan bu bilgi kaynağı kaybolma riski altındadır. Halkımızın etnobotanik kültürünün kayıtlı hale getirilmesi bakımından bilimsel nitelikli etnobotanik araştırmalar çok önemlidir. Özellikle gıda sektöründe etkili olarak kullanılan katkı maddelerinin varlığı ve zararlı etkileri, sentetik maddelerden ilaç yapımı ve istenmeyen yan etkileri nedeniyle biyolojik kökenli ürünlere artan ilgi ve buna paralel olarak etnobotanik bilgi birikimine verilmesi gereken önem her geçen gün artmaktadır.

Türkiye'de etnobotanik üzerine yapılan bilimsel çalışmaların tarihi Cumhuriyet tarihi ile sınırlıdır (Baytop 1999). Halkın kırsal kesimde yaşayan kısmı, bitkileri geçmişte olduğu gibi geleneksel yöntemlerle kullanmaya devam etmektedir (Saraç ve ark. 2013, Polat ve ark.
2015). Son yıllarda tıbbi ve aromatik bitkiler üzerinde çok sayıda çalışma yapılmıştır (Çakılcıoğlu ve ark. 2007, Polat ve ark. 2012, Saraç ve ark. 2013, Akbulut 2015, Eminağaoğlu ve ark. 2017, Karaköse ve ark. 2019).

Artvin, coğrafi konumu, jeomorfolojik yapısı ve farklı iklim türlerinin etkisi sayesinde zengin bir floraya sahiptir. Artvin florasında 137 familyada 761 cinse ait 2727 takson listelenmiştir (Eminağaoğlu 2015). Floradaki bu çeşitlilik nedeniyle zengin tıbbi bitki kaynağına sahip Artvin'de, yerel insanların çoğunluğu bitkileri geleneksel olarak kullanmaktadır (Eminağaoğlu ve ark. 2015, Eminağaoğlu ve ark. 2017). Ancak, bu konudaki araştırmalar ArtvinYusufeli Kılıçkaya köyü ve çevresinde (Alkan 2019), Borçka Camili Biyosfer rezerv alanında (Eraydın 2010) ve Hatila Vadisi Milli Parkı ve çevresinde (Eminağaoğlu ve ark. 2017) yapılan birkaç çalışma ile sınırlıdır.

Bu çalışmada, Artvin ili merkez köylerinde yaşayan halkın kullandığı tıbbi bitkilerin yöresel ve bilimsel adlarının tespit edilmesi, kullanım amaçları, kullanılan kısımları ve kullanım şekillerinin belirlenmesi ile elde edilen bilgilerin kaydedilmesi amaçlanmıştır. Böylece, yörenin etnobotanik özelliklerinin belirlenerek, bu bilgi birikiminin ve kültürünün gelecek nesillere ulaştırılmasına katkı sağlanacaktır.

\section{MATERYAL METOD}

Türkiye'nin kuzey doğusunda yer alan Artvin, Holarktik bölgenin Avrupa Sibirya flora alanının kolşik kesiminde bulunmaktadır. Artvin merkez ve çevresinde kışları soğuk ve yaz yağışlarının daha az olduğu Karadeniz iklimi görülür. Ayrıca, tüm Çoruh vadisi boyunca görülen Akdeniz iklimi etkisi ile yazları sıcak ve kurak, kışları ise karasal iklime kıyasla kısmen daha ılıman ve daha az yağış alan bir mikro iklim görülür (Eminağaoğlu ve ark. 2015). Doğal bitki taksonu sayısı ile Türkiye'nin en zengin ili olan Artvin'de 198'i endemik, 302'si endemik olmayan nadir olmak üzere toplam 500 adet bitki risk altındadır. Artvin'de pseudomaki, dere, orman, alpin ve subalpin vejetasyonu gibi farklı yükseltilerde farklı vejetasyon tipleri yayılış göstermektedir (Eminağaoğlu ve ark. 2015).

Araştırma materyali bitkiler, 2016-2019 yılları arasında, Artvin ili merkez ilçesine bağlı, 7 mahalle (Balcıoğlu, 
Çamlık, Çarşı, Çayağzı, Dere, Orta, ve Yeni) ve 36 merkez köyden (Ağıllar, Ahlat, Alabalık, Aşağımaden, Bağcılar, Bakırköy, Ballıüzüm, Beşağıl, Çimenli, Derinköy, Dikmenli, Dokuzoğul, Erenler, Fıstıklı, Hamamlı, Hızarlı, Kalburlu, Köseler, Okumuşlar, Ormanlı, Ortaköy, Oruçlu, Pırnalı, Sakalar, Salkımlı, Sarıbudak, Seyitler, Sünbüllü, Şehitlik, Taşlıca, Tütüncüler, Varlık, Vezirköy, Yanıklı, Yukarımaden, Zeytinlik) toplandı. Toplanan bitki örnekleri teşhisleri yapılarak (Davis 1965-1985, Davis ve ark. 1988), Artvin Çoruh Üniversitesi herbaryumuna (ARTH) yerleştirildi. Bitkilerin genel isimleri Güner ve ark. (2012) eserine göre verildi.

Bu çalışmada, yerel halktan 138 kişi ile yüz yüze yapılan görüşmelerde, kullandıklarını belirttikleri tıbbi bitkilerden örnekler alındı ve uygulanan anket ile bu tıbbi bitkilerin yöresel kullanımları, kullanılan kısımları, hazırlama ve kullanma yöntemleri ve yerel isimleri kaydedildi. Ayrıca, ankete katılanların yaş, cinsiyet, eğitim düzeyi, meslek gibi demografik özellikleri belirlendi (EK 1). Köylerde yaşayan yerel halktan ankete katılanların \% 31.88'i (44 kişi) kadın,

Çizelge 1. Katılımcıların demografik özellikleri

\begin{tabular}{lcc}
\hline Özellikler & Katılımcı sayısı & Yüzde değeri \\
\hline Cinsiyet & & \\
\hline Kadın & 44 & 31.88 \\
Erkek & 94 & 68.12 \\
\hline Eğitim düzeyi & & \\
\hline Okula gitmeyen & 7 & 5.10 \\
İlkokul mezunu & 55 & 39.85 \\
Ortaokul mezunu & 27 & 19.56 \\
Lise mezunu & 30 & 21.73 \\
Üniversite mezunu & 19 & 13.76 \\
\hline Yaşaralığı & & \\
\hline $21-25$ & 6 & 4.34 \\
$26-40$ & 14 & 10.14 \\
$41-65$ & 74 & 53.64 \\
$66-84$ & 44 & 31.88 \\
\hline Meslek & & \\
\hline Çiftçi & 16 & 11.60 \\
Emekli & 52 & 37.68 \\
Esnaf & 5 & 3.62 \\
Ev hanımı & 26 & 18.84 \\
İşçi & 22 & 15.94 \\
Memur & 12 & 8.70 \\
Öğrenci & 2 & 1.45 \\
Serbest meslek & 3 & 2.17 \\
\hline
\end{tabular}

\% 68.12'si (94 kişi) erkektir. Katılımcıların yaş aralığı 21-84 iken, \% 85.52'si 40 yaş ve üzerindedir. Katılımcıların demografik özellikleri Çizelge 1 'de verilmiştir.

Farklı yerel katılımcılardan elde edilen bilgilerin homojenliğini hesaplamak, benzerlik ve farklııklarını ortaya koymak ve kullanılan bitkilerin önemini belirlemek için farklı nicel indeksler (UV, FIC, FL) kullanılmıştır. Yerel olarak bilinen ve kullanılan her bitkinin önemini gösteren kullanım değeri (UV), her bitki türünün kullanım sayısının (U) toplam katılımcı sayısına (N) oranı ile belirlendi (Trotter ve Logan 1986, Albuquerque ve ark. 2006, Abe ve Ohtani 2013, Eminağaoğlu ve ark. 2017, Karaköse ve ark. 2019).

$\mathrm{FIC}=\mathrm{Nur}-\mathrm{Nt} /(\mathrm{Nur}-1)$ (Faktor Informants Consensus) formülü (Trotter ve Logan 1986) kullanılarak katılımcılar için fikir birliği faktörü hesaplandı. Hesaplanan FIC değerleri 0 ile 1 arasında değişmektedir ve ' 1 ' en yüksek onay seviyesini göstermektedir. 'Nur' herhangi bir hastalık ya da hastalık grubu için bilgi veren katılımcı sayısını, 'Nt' herhangi bir hastalık ya da hastalık grubu için kullanılan bitki türü sayısını ifade eder. FIC değeri, çeşitli hastalık kategorileri için çalışma alanında bitkilerin kullanımı ile ilgili bilgi verenler arasında fikir birliği olup olmadığını analiz etmek için kullanılır (Heinrich ve ark. 1998). FL değeri (uygunluk-geçerlik düzeyi) belirli bir tür için aynı tıbbi kullanımı bildirenlerin sayısının, herhangi bir türün tıbbi kullanımını bildirenlerin sayısına oranının yüzdesi olarak tanımlanmıştır. Böylece, bir hastalık kategorisinde tedavi için kullanılan bitkilerin kullanım yoğunluğu belirlenmiştir (Friedman ve ark. 1986, Eminağaoğlu ve ark. 2017, Karaköse ve ark. 2019).

Yerel halkın tıbbi bitkileri kullanma amacına göre; kalp damar hastalıkları (kalp damar hastalıkları, kolesterol, tansiyon, kan sulandırıcı), endokrin sistem hastalıkları (şeker hastalığı, guatr), üriner sistem hastalıkları (prostat, böbrek ve idrar yolu iltihabı veya enfeksiyonu, idrar artırıcı veya söktürücü, kum ve taş düşürücü), solunum sistemi hastalıklar; akciğer hastalıkları (astım, bronşit, balgam söktürücü, nefes açıcı), üst solunum yolu hastalıkları (nezle, grip, soğuk algınlığı, öksürük, boğaz ağrısı,), iç hastalıkları; mide rahatsızlıkları (ülser, gastrit, yanma), bağırsak rahatsızlıkları (ishal, karın ağrısı, 
kabızlık), karaciğer rahatsızıkları (sarılık), cilt hastalıkları (yara, iltihaplı yara, çıban, yanık, nasır, siğil), kas ve eklem hastalıkları (romatizma, kireçlenme, diz ağrısı, kemik ve eklem ağrıları, kan toplama, burkulma, bel fitığı), kanser olmak üzere hastalık grupları oluşturulmuştur.

\section{BULGULAR VE TARTIŞMA}

Araştırma alanında, yöre halkı tarafından, tıbbi amaçlarla 27 familyaya ait 43 farklı bitkinin kullanıldığı tespit edilmiştir. Tespit edilen bitkilerin biri hariç (Zea mays) tamamı Magnoliophyta (Magnoliidae) sınıfında yer almaktadır. Bu bitkilerin 23'ü otsu, 11'i ağaç, 4'ü çalı, 3'ü bodur çalı-sarılıcı ve 1 tanesi yarı parazittir (Çizelge 2). Tarımı yapılan Zea mays dışındaki bitkiler doğal yayılış gösterir. Bu çalışmada, Eminağaoğlu ve ark. (2017)'nın çalışma sonucuna benzer şekilde, tıbbi olarak en çok kullanılan türleri barındıran önemli familyalar Rosaceae, Asteraceae, Lamiaceae olarak ön plana çıkmıştır.

Bitkilerin en çok tercih edilen kullanım şekli infüzyondur (\%58.14). Bu kullanım şeklini Karaköse ve ark. (2019)'nın çalışmasında olduğu gibi dekoksiyon ve taze olarak (\%20.93) tüketim izler. Sonra sırasıyla, bitki reçinesi veya özsuyunun sürülmesi (\%9.30), yemek olarak yenilmesi (\%9.30), taze ezilerek veya kurutularak (\%6.98), lapa (\%4.65), ezilerek çıkarılan yağ (\%4.65), tıbbi yağ olarak, çiğneyip-yutarak ve kaynatılarak (\%2.33) kullanıldıkları bildirilmiştir (Şekil 1).

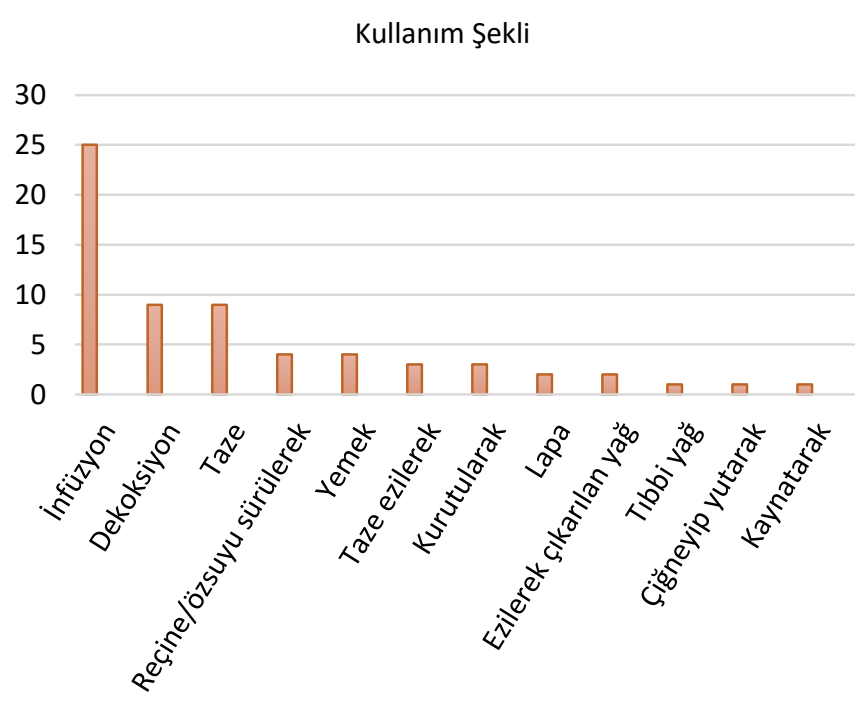

Şekil 1. Tıbbi bitkilerin kullanım şekilleri
Bitkilerin en çok kullanılan kısımları yaprak (\%44.19), çiçek (\%16.28) ve meyve (\%11.63) (Şekil 2) olarak sıralanmıştır. Araştırma alanına yakın bölgelerde yapılan diğer çalışmalarda da en çok kullanılan ilk üç bitki kısmı aynıdır (Akbulut ve Özkan 2014, Karaköse ve ark. 2019). Onları \%9.30 ile bitkinin kökü hariç tamamının kullanılması, \%6.98 ile kök, gövde ve sürgünler, \%4.65 tohum, kozalak, reçine, özsuyu, \%2.33 ile bitkilerin sakız, odun, dal, stiluslar, yumru, meyve sapı ve tohum perdesi gibi kısımları izler (Şekil 2).

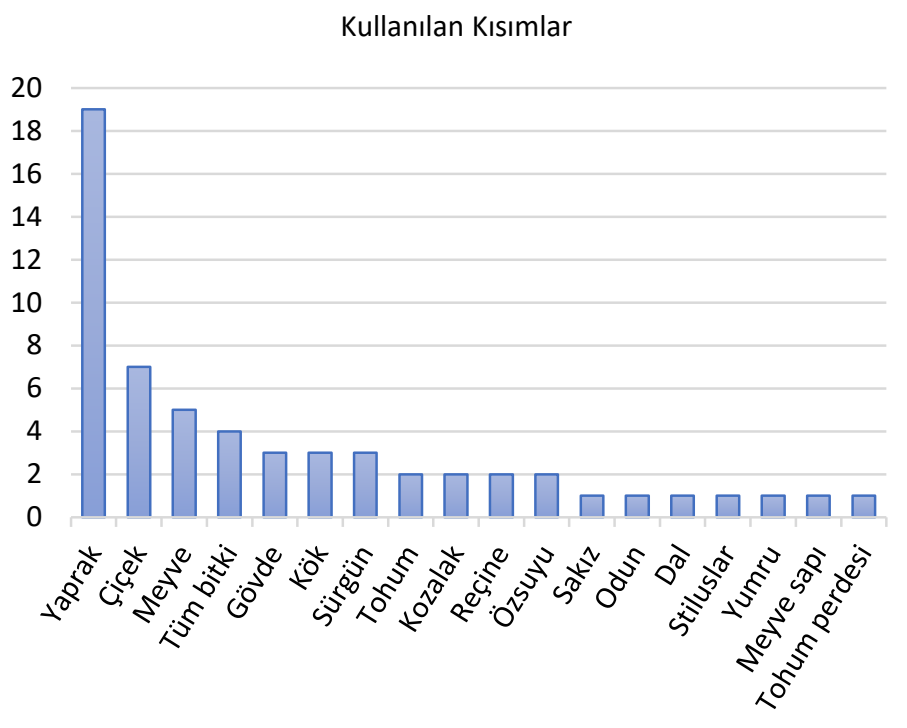

Şekil 2. Tıbbi bitkilerin kullanılan kısımları 
Çizelge 2. Yöresel olarak kullanılan tıbbi bitkiler

\begin{tabular}{|c|c|c|c|c|c|c|c|}
\hline Familya & Bilimsel Adı & Türkçe adı & Yöresel Adı & Kullanılan kısmı & Kullanım şekli & Kullanılışı & UV \\
\hline \multirow{2}{*}{ Cupressaceae } & Juniperus oxycedrus L. & \multirow{2}{*}{ Katran ardıcı } & \multirow{2}{*}{ Ardıç } & \multirow{2}{*}{ Kozalak } & 1. Dekoksiyon & 1. Şeker hastalığı & \multirow{2}{*}{0.01} \\
\hline & ARTH 15802 & & & & 2. Ezilerek çıkarılan yağ (katran-özüt) & 2. Eklem ağrıları & \\
\hline \multirow{6}{*}{ Pinaceae } & Picea orientalis (L.) Peterm. & Do־̆ & Kälnor Cölnor & 1. Sakız & 1. Çiğnenir ve yutulur & 1. Mide rahatsızlıkları & רח0 \\
\hline & ARTH 15804 & Dugu Laúmi & NUKndI, GOKIIII & 2. Reçine & 2. Sürülür & 2. Ilttihaplı yaralar & 0.02 \\
\hline & & \multirow{4}{*}{ Sarıçam } & \multirow{4}{*}{ Çam } & 1. Reçine & 1. Kaynatılıp soğutularak yapılan haplar yutulur & 1. Mide ülseri & \multirow{4}{*}{0.04} \\
\hline & Pinus sylvestris $\mathrm{L}$. & & & 2. Reçine & 2. zeytinyağı ve balmumu ile karıştırılıp sürülür & 2. Yara & \\
\hline & ARTH 15806 & & & 3. Yeşil kozalak & 3. İnfüzyon veya Dekoksiyon & 3. Öksürük & \\
\hline & & & & 4. Odun & 4. Isıtılarak, üzerine oturulur & 4. İshal, karın ağrısı & \\
\hline \multirow{5}{*}{ Asteraceae } & $\begin{array}{l}\text { Achillea millefolium L. } \\
\text { ARTH } 15810\end{array}$ & $\begin{array}{l}\text { Beyaz } \\
\text { civanperçemi }\end{array}$ & Tırtıllı ot & Yaprak & Taze & $\begin{array}{l}\text { Yara iyileştirme, Kanama } \\
\text { durdurma }\end{array}$ & 0.007 \\
\hline & $\begin{array}{l}\text { Achillea sp. } \\
\text { ARTH } 15811\end{array}$ & Civanperçemi & Dağçayı & Çiçek & İnfüzyon & $\begin{array}{l}\text { Akciğer rahatsızlıkları, } \\
\text { Soğuk algınlığı, Nefes açıcı }\end{array}$ & 0.03 \\
\hline & $\begin{array}{l}\text { Helichrysum armenium DC. } \\
\text { ARTH } 15813\end{array}$ & Altın otu & Altın otu & Çiçek & İnfüzyon & Kan sulandırıcı, iltihap atıcı & 0.01 \\
\hline & Tripleurospermum sp. & \multirow{2}{*}{ Papatya } & \multirow{2}{*}{ Beyaz papatya } & \multirow{2}{*}{ Çiçek } & \multirow{2}{*}{$\begin{array}{l}\text { 1. İnfüzyon } \\
\text { 2. Taze ısırılır, çiğnenir }\end{array}$} & $\begin{array}{l}\text { 1.Astım, bronşit, kalp } \\
\text { rahatsızıkları }\end{array}$ & \multirow{2}{*}{0.02} \\
\hline & ARTH 15817 & & & & & 2. Ağız yaraları, diş ağrıları & \\
\hline Ebenaceae & $\begin{array}{l}\text { Diospyros lotus L. } \\
\text { ARTH } 15822\end{array}$ & Hırnık & Kara hurma & Meyve & Taze- kuru yenir & Kabızlık & 0.007 \\
\hline Equisetaceae & $\begin{array}{l}\text { Equisetum arvense L. } \\
\text { ARTH } 15823\end{array}$ & Atkuyruğu & $\begin{array}{l}\text { Kırkkilit, kırkkana, } \\
\text { katara, kırkboğum, } \\
\text { katırkuyruğu }\end{array}$ & Yaprak & İnfüzyon (kurutularak) & $\begin{array}{l}\text { Prostat, idrar söktürücü, kum } \\
\text { ve taş düşürücü, kemik ağrıları }\end{array}$ & 0.03 \\
\hline Ericaceae & Rhododendron luteum Sweet & Sarıçiçekli & Yel Yeli Kumar & 1.Yaprak (yazın) & 1. İnfüzyon (Banyo) & Romatizm ว־̆rılar & 0 \\
\hline & ARTH 15824 & orman gülü & rea, reil, kumial & 2. Dalları (kışın) & 2. Dekoksiyon (Banyo) & Romatizma agriları & 0.007 \\
\hline Euphorbiaceae & $\begin{array}{c}\text { Euphorbia spp. } \\
\text { ARTH } 15825\end{array}$ & Sütleğen & Sütlü ot & Özsuyu & Gövdesi kırılarak, sürülür & Nasır, siğil & 0.007 \\
\hline \multirow{3}{*}{ Fabaceae } & Onobrychis cornuta (L.) Desv. & Kuşkaçıran & Geven & 1. Gövde, kök & 1. Ezilerek elde edilen özü-yağı sürülür & Bel fıtığı ağrısı & 0.007 \\
\hline & ARTH 15863 & & & 2. Yaprak, gövde & 2. İnfüzyon, Dekoksiyon & & \\
\hline & $\begin{array}{l}\text { Trifolium pratense L. } \\
\text { ARTH } 15864\end{array}$ & Çayır gülü & Üçkulak & Yeşil kısımları & Taze ezilerek sürülür & Yara iyileştirici & 0.007 \\
\hline Hypericaceae & $\begin{array}{l}\text { Hypericum perforatum L. } \\
\text { ARTH } 15828\end{array}$ & Sarı kantaron & $\begin{array}{l}\text { Sarı kantoron otu, } \\
\text { Kantoron otu }\end{array}$ & $\begin{array}{l}\text { Tüm bitki } \\
\text { (kök hariç) }\end{array}$ & $\begin{array}{l}\text { 1. Tıbbi yağ } \\
\text { 2. İnfüzyon }\end{array}$ & $\begin{array}{l}\text { 1. Yara iyileştirici, diz ağrıları } \\
\text { 2. Bağırsak ve mide } \\
\text { rahatsızlıkları }\end{array}$ & 0.01 \\
\hline
\end{tabular}

322 / F. Erşen Bak, K. Çifci / AÇÜ Orman Fak Derg 21(2):318-329 (2020) 
Çizelge 2. (devamı) Yöresel olarak kullanılan tıbbi bitkiler

\begin{tabular}{|c|c|c|c|c|c|c|c|}
\hline Juglandaceae & $\begin{array}{l}\text { Juglans regia L. } \\
\text { ARTH } 15829\end{array}$ & Ceviz & Ceviz & $\begin{array}{l}\text { 1.Tohum içi perde } \\
\text { 2. Erkek çiçek }\end{array}$ & İnfüzyon & $\begin{array}{l}\text { 1. Kolesterol, öksürük } \\
\text { 2. Saç bakımı }\end{array}$ & 0.03 \\
\hline \multirow{3}{*}{ Lamiaceae } & $\begin{array}{l}\text { Origanum rotundifolium Boiss. } \\
\text { ARTH } 15830\end{array}$ & $\begin{array}{l}\text { Yuvarlak } \\
\text { mercan }\end{array}$ & Aylık otu & $\begin{array}{l}\text { Tüm bitki } \\
\text { (kök hariç) }\end{array}$ & Kaynatılarak (Banyo) & Bebek gaz sancısı & 0.01 \\
\hline & $\begin{array}{l}\text { Satureja spicigera (K.Koch) Boiss } \\
\text { Satureja hortensis L. } \\
\text { ARTH 15831-15832 }\end{array}$ & Çorba kekiği & Kondar, köndar & $\begin{array}{l}\text { 1. Yaprak, sürgün } \\
\text { 2. Yaprak }\end{array}$ & $\begin{array}{l}\text { 1. Kurutulup lor çorbasına baharat } \\
\text { olarak katılarak yenir. } \\
\text { 2. İnfüzyon }\end{array}$ & $\begin{array}{l}\text { 1. Boğaz ağrısı, mide rahatsızlıkları } \\
\text { 2. İdrar söktürücü }\end{array}$ & 0.11 \\
\hline & $\begin{array}{l}\text { Thymus praecox Opiz } \\
\text { ARTH } 15869\end{array}$ & Yayla kekiği & $\begin{array}{l}\text { Dağ çayı, } \\
\text { Dağ kekiği }\end{array}$ & Yaprak, Çiçek & İnfüzyon & $\begin{array}{l}\text { Kalp-damar hastalıkları, } \\
\text { kolesterol, soğuk algınlığı }\end{array}$ & 0.02 \\
\hline \multirow[t]{2}{*}{ Malvaceae } & $\begin{array}{l}\text { Malva neglecta L. } \\
\text { ARTH } 15871\end{array}$ & Ebegümeci & Molok, Molokvi & Yaprak & $\begin{array}{l}\text { 1. Lapa (arpa unu ile) pişirilir, sarılır } \\
\text { 2. Yemeği yenir }\end{array}$ & $\begin{array}{l}\text { 1. Ağrıyan yara ve çıbanlara } \\
\text { 2. Balgam söktürücü, mide } \\
\text { rahatsızııları }\end{array}$ & 0.04 \\
\hline & $\begin{array}{l}\text { Tilia rubra subsp. caucasica } \\
\text { (Rupr.) V. Engl. } \\
\text { ARTH } 15833\end{array}$ & Ihlamur & Ihlamur & Çiçek & İnfüzyon & Soğuk algınlığı & 0.38 \\
\hline Moraceae & $\begin{array}{r}\text { Ficus carica L. } \\
\text { ARTH } 15872\end{array}$ & İncir & İncir & Yaprak & Dekoksiyon & Öksürük, balgam söktürücü & 0.01 \\
\hline \multirow{2}{*}{ Oleaceae } & $\begin{array}{l}\text { Olea europaea L. } \\
\text { ARTH } 15874\end{array}$ & Zeytin & Zeytin & $\begin{array}{l}\text { 1. Meyve } \\
\text { 2. Yaprak } \\
\text { 3. Yaprak }\end{array}$ & $\begin{array}{l}\text { 1. Dövülüp, ezilerek sarılır } \\
\text { 2. İnfüzyon (ökse otu ile karıştırılarak) } \\
\text { 3. İnfüzyon }\end{array}$ & $\begin{array}{l}\text { 1. Kan toplama, burkulma } \\
\text { 2. Kolesterol } \\
\text { 3. Şeker hastalığı }\end{array}$ & 0.03 \\
\hline & $\begin{array}{l}\text { Osmanthus decorus (Boiss.\& } \\
\text { Balansa) Kasapligil } \\
\text { ARTH } 15834\end{array}$ & Poci & Şekem & $\begin{array}{l}\text { 1. Meyve } \\
\text { 2. Yaprak }\end{array}$ & $\begin{array}{l}\text { 1. Taze yenir } \\
\text { 2. İnfüzyon }\end{array}$ & İç hastalıkları & 0.007 \\
\hline Papaveraceae & $\begin{array}{l}\text { Chelidonium majus L. } \\
\text { ARTH } 15835\end{array}$ & Kırlangıç çiçeği & Sarı ot & $\begin{array}{l}\text { 1. Özsuyu } \\
\text { 2. Yaprak }\end{array}$ & $\begin{array}{l}\text { 1. Sürülür } \\
\text { 2. Taze olarak, basılarak sarılır }\end{array}$ & $\begin{array}{l}\text { 1. Yara, yanık } \\
\text { 2. Çıban }\end{array}$ & 0.03 \\
\hline Plantaginaceae & $\begin{array}{l}\text { Plantago major } \mathrm{L} . \\
\text { Plantago lanceolata L. } \\
\text { ARTH 15837-15838 }\end{array}$ & $\begin{array}{l}\text { Sinir otu } \\
\text { Damarlıca }\end{array}$ & $\begin{array}{l}\text { Damarlı ot, sinirli } \\
\text { ot, lağvazan, } \\
\text { lağvazava, } \\
\text { balazga, } \\
\text { tivazarvğa }\end{array}$ & $\begin{array}{l}\text { 1. Yaprak } \\
\text { 2. Yaprak } \\
\text { 3. Yaprak }\end{array}$ & $\begin{array}{l}\text { 1. Ezilerek veya haşlanarak sürülür } \\
\text { 2. İnfüzyon } \\
\text { 3. Taze ezilerek koklanır }\end{array}$ & $\begin{array}{l}\text { 1.Yara ve kör çıban tedavisi, } \\
\text { 2.Sakinleştirici, kireçlenme, } \\
\text { idrar yolu enfeksiyonu, guatr, } \\
\text { kalp rahatsızlıkları } \\
\text { 3. Sinüzit }\end{array}$ & 0.24 \\
\hline Platanaceae & $\begin{array}{l}\text { Platanus orientalis L. } \\
\text { ARTH } 15875\end{array}$ & Çınar & Çınar & Yaprak & İnfüzyon & Eklem ağrıları, kireçlenme & 0.01 \\
\hline Poaceae & $\begin{array}{l}\text { Zea mays L. } \\
\text { ARTH } 15876\end{array}$ & Misır & Misır & Stilus (püskül) & İnfüzyon & $\begin{array}{l}\text { Şeker hastalığı, idrar artırıcı, } \\
\text { idrar yolu iltihabı }\end{array}$ & 0.007 \\
\hline
\end{tabular}


Çizelge 2. (devamı) Yöresel olarak kullanılan tıbbi bitkiler

\begin{tabular}{|c|c|c|c|c|c|c|c|}
\hline \multirow[b]{2}{*}{ Polygonaceae } & $\begin{array}{l}\text { Polygonum bistorta L. } \\
\text { ARTH } 15877\end{array}$ & Dağ lahanası & $\begin{array}{l}\text { Dağ pancarı, yayla } \\
\text { pancarı, tutya, } \\
\text { tivrihali, olin }\end{array}$ & Yaprak & Sütlü çorbası ve yemeği yenir & $\begin{array}{l}\text { Kansere karşı koruyucu, } \\
\text { boğaz ağrısı, mide rahatsızlıkları }\end{array}$ & 0.03 \\
\hline & $\begin{array}{l}\text { Rumex spp. } \\
\text { ARTH } 15878\end{array}$ & Yabani labada & $\begin{array}{l}\text { Ğalo, evelek, } \\
\text { labada, ekşi ot }\end{array}$ & $\begin{array}{l}\text { 1. Yaprak } \\
\text { 2. Gövde }\end{array}$ & $\begin{array}{l}\text { 1. Yaprakları haşlanıp yoğurtla yenir, } \\
\text { kavrularak sade ya da bulgurlu } \\
\text { yemeği yapılıp yenir } \\
\text { 2. Taze yenir }\end{array}$ & Tansiyon, kolesterol & 0.01 \\
\hline Primulaceae & $\begin{array}{l}\text { Cyclamen coum Mill } \\
\text { ARTH } 15880\end{array}$ & Yer somunu & Sıklamen & Yumru & Dekoksiyon & Sarılık & 0.01 \\
\hline Ranunculaceae & $\begin{array}{l}\text { Ranunculus cappadocicus Willd. } \\
\text { ARTH } 15845\end{array}$ & Yağlı çanak & Salika & $\begin{array}{l}\text { Tüm bitki } \\
\text { (kök hariç) }\end{array}$ & $\begin{array}{l}\text { Taze halde ceviz kabuğuna doldurulup } \\
\text { dize sarılır, yara açmak için }\end{array}$ & $\begin{array}{l}\text { Romatizma, } \\
\text { diz ağrısı (eklem ödemi) }\end{array}$ & 0.01 \\
\hline Rhamnaceae & $\begin{array}{l}\text { Paliurus spina-christi P. Mill. } \\
\text { ARTH } 15846\end{array}$ & Karaçalı & Kara diken & $\begin{array}{l}\text { Tohum, taze } \\
\text { sürgün }\end{array}$ & İnfüzyon / dekoksiyon & Böbrek ve idrar yolları & 0.02 \\
\hline \multirow{5}{*}{ Rosaceae } & $\begin{array}{r}\text { Alchemilla sp. } \\
\text { ARTH } 15847\end{array}$ & Aslanpençesi & Dağ çayı & Yaprak, Çiçek & İnfüzyon & $\begin{array}{l}\text { Akciğer hastalıkları, böbrek } \\
\text { rahatsızıkları }\end{array}$ & 0.01 \\
\hline & $\begin{array}{l}\text { Cerasus avium L. Moench } \\
\text { ARTH } 15848\end{array}$ & Kiraz & Kiraz & Meyve sapı & Dekoksiyon & $\begin{array}{l}\text { İdrar söktürücü, iltihap kurutucu, } \\
\text { soğuk algınlığı }\end{array}$ & 0.03 \\
\hline & $\begin{array}{l}\text { Cydonia oblonga Mill. } \\
\text { ARTH } 15882\end{array}$ & Ayva & Ayva & $\begin{array}{l}\text { Yaprak, } \\
\text { Meyve kabuğu }\end{array}$ & İnfüzyon & Öksürük & 0.02 \\
\hline & $\begin{array}{r}\text { Rosa canina L. } \\
\text { ARTH } 15851\end{array}$ & Kuşburnu & Kuşburnu & Kurutulmuş meyve & İnfüzyon & Soğuk algınlığı, kanser & 0.10 \\
\hline & $\begin{array}{l}\text { Rubus spp. } \\
\text { ARTH } 15885\end{array}$ & Böğürtlen & $\begin{array}{l}\text { Böğürtlen, } \\
\text { tikanın gakası }\end{array}$ & Kök & Dekoksiyon & Şeker hastalığı & 0.07 \\
\hline Santalaceae & $\begin{array}{l}\text { Viscum album L. } \\
\text { ARTH } 15887\end{array}$ & Ökse otu & $\begin{array}{l}\text { Fitri, titri, } \\
\text { kitri, bitri }\end{array}$ & $\begin{array}{l}\text { Tüm bitki } \\
\text { (meyve hariç) }\end{array}$ & İnfüzyon & $\begin{array}{l}\text { Şeker hastalığı, kolesterol, kalp- } \\
\text { damar hastalıkları, ciğerleri } \\
\text { temizlemek }\end{array}$ & 0.05 \\
\hline Urticaceae & $\begin{array}{l}\text { Urtica dioica L. } \\
\text { ARTH } 15853\end{array}$ & Isırgan & $\begin{array}{l}\text { Zincar, Cincar, } \\
\text { Cimcar }\end{array}$ & $\begin{array}{l}\text { 1.Yaprak ve sürgün } \\
\text { 2. Tohum } \\
\text { 3. Yaprak } \\
\text { 4. Taze bitki }\end{array}$ & $\begin{array}{l}\text { 1. Çiçekleri tohuma dönmeden, yemek } \\
\text { ve çorbası yapılarak yenir } \\
\text { 2. Bal veya pekmezle karıştırılarak yenir } \\
\text { 3. İfüzyon } \\
\text { 4. Taze bitki vücuda temas ettirilir }\end{array}$ & $\begin{array}{l}\text { 1- } 2 \text {. Kanser, astım, bronşit } \\
\text { 3. Direnç artırıcı, idrar söktürücü, } \\
\text { romatizma } \\
\text { 4. Romatizma }\end{array}$ & 0.07 \\
\hline Violaceae & $\begin{array}{l}\text { Viola suavis M. Bieb. } \\
\text { ARTH } 15854\end{array}$ & Akgözmenekşe & Zukantela & Kök, kök boğazı & Soyularak taze yenir & Nezle, grip, güneş çarpması & 0.02 \\
\hline Zygophyllaceae & $\begin{array}{l}\text { Tribulus terrestris L. } \\
\text { ARTH } 15856\end{array}$ & $\begin{array}{l}\text { Çoban } \\
\text { çökerten }\end{array}$ & Lastik patlatan & $\begin{array}{l}\text { Gövde, yaprak, } \\
\text { sürgün }\end{array}$ & İnfüzyon & Kalp-damar hastalıkları & 0.01 \\
\hline
\end{tabular}


Araştırma alanında tıbbi amaçlarla kullanılan çok sayıda bitki ön plana çıkmıştır. Juniperus oxycedrus kozalakları şeker hastalığı ve eklem ağrılarına karşı, Helichrysum armenium'un çiçekleri kan sulandırıcı ve iltihap atıcı olarak kullanılır (Çizelge 2). Thymus praecox' un yaprak ve çiçeklerinden kalp-damar hastalıkları, kolesterol ve soğuk algınlığına karşı çay yapılarak içilir. Tribulus terrestris kalpdamar hastalıkları için infüzyon halinde kullanılır. Cyclamen coum yumruları sarılık hastalığına karşı kaynatılarak içilir. Viola suavis'in soyularak yenen kök ve kök boğazı nezle ve grip için antibiyotik etkisi gösterir, güneş çarpmasına iyi gelir. İç hastalıkları için Osmanthus decorus'un yaprakları kaynatılarak içilir, meyveleri ise yenilir (Çizelge 2). Osmanthus decorus'un tıbbi kullanımı ile ilgili olarak ülkemizde herhangi bir bulguya rastlanmamış, farklı kültürlerde diğer Osmanthus türlerinin kısıtlı kullanımından bahsedilmiştir. Amerika'da kabuklarının kanamayı durdurucu, müshil ve ağrı kesici etkileri nedeniyle kullanıldığı, yağlı meyvelerinin ise yenilebilir olduğu belirtilmiştir (Austin 2004). Ayrıca, Eminağaoğlu ve ark. (2017) Thymus praecox'den yapılan lapanın karın ağrısı ve soğuk algınlığı için yenildiğini bildirmiştir. Ertuğ (2002) kalp için şifalı olan Tribulus terrestris bitkisinin tohum ve yapraklarının kum ve taş düşürmede ve tansiyon düşürmede etkili olduğunu belirtmiştir.

Önceki çalışmalarda, Artvin yöresinde (Çizelge 2) çeşitli tıbbi amaçlarla kullanılan Tilia sp. (Akan ve Bakır 2015), Paliurus spina-christi (Nacakçı ve Dutkuner 2018, Çakılcıoğlu ve ark. 2007), Equisetum arvense (Saraç ve ark. 2013, Akan ve Bakır Sade 2015), Tripleurospermum sp. (Karakurt 2014), Viscum album (Deniz ve ark. 2010) taksonlarının aynı amaçlarla kullanımları bildirilmiştir. Urtica dioica'nın (Çakılcıoğlu ve ark. 2007) ve Plantago türlerinin (Arı 2014, Akan ve Bakır Sade 2015, Çakılcıoğlu ve ark. 2007) çeşitli bölgelerde haricen ve dâhilen benzer amaçlarla kullanımlarından söz edilmiştir. Juglans regia'nın kolesterol düşürücü olarak kullanımı dışında, kuvvetlendirici, sindirim sistemi rahatsızlıkları, şeker hastalığı, unutkanlık ve kansızlığa karşı (Akbulut 2015, Saraç ve ark. 2013), kurt düşürücü, astım, incinme ağrılarına karşı (Saraç ve ark. 2013) kullanımları bildirilmiştir. Rosa canina'nın Artvin'deki gibi soğuk algınlığına karşı ve ayrıca idrar yolu enfeksiyonu ve basur tedavisinde kullanıldığı bildirilmiştir (Nacakçı ve Dutkuner 2018, Arı 2014, Akan ve Bakır Sade 2015). Cydonia oblonga'nın yaprak ve çiçeklerinin nefes darlığı, öksürük kesmek, bronşit, verem ve kanın temizlenmesi (Savran ve ark. 2008, Kargığlu ve ark. 2008), ishale karşı (Deniz ve ark. 2010, Akbulut 2015) kullanıldığı daha önceki bazı çalışmalarda kaydedilmiştir. Koçyiğit (2005) Olea europaea yapraklarının dekoksiyonunun dâhilen kan şekerini ve kolesterolü düşürmek için kullanıldığını, Sarıkan (2007) ise infüzyonunun şeker hastalığında kullanıldığını belirtmiştir. Malva neglecta'nın Artvin bölgesinde belirtilen tıbbi kullanımları dışında yaprak ve çiçeklerinden (dekoksiyon), solunum sistemi rahatsızlığı, böbrek iltihabı, antioksidan olarak ve kansere karşı (Akbulut 2015); kökünden (dekoksiyon) ise boğaz ve bademcik iltihabına karşı (Deniz ve ark. 2010) faydalanıldığı bildirilmiştir.

Tıbbi amaçla kullanılan bitkilerin bazıları yemek ve içmek dışında, farklı şekillerde de kullanılmaktadır. Örneğin, Trifolium pratense, Malva sylvestris ve Plantago spp. bitkilerinin taze olarak ezilen yapraklarının, Chelidonium majus'un özsuyunun, Hypericum perforatum'dan üretilen tıbbi yağın yanık, yara ve çıbanların iyileştirilmesinde kullanıldığı bildirilmiştir. Euphorbia türlerinin özsuyu nasır ve siğillerin tedavisinde kullanılır. Baykal (2015) ve Arı (2014) Plantago türlerinin, Artvin'deki bulgulara benzer şekilde, ezilen taze yapraklarının yaraların iyileştirilmesinde ve kanama durdurmak amacıyla kullanıldığı bildirmiştir. Elazığ ve Uşak bölgesinde Plantago türlerinin yaprakları ve Rize-Güneysu bölgesinde ise Malva sylvestris ve Plantago türlerinin yaprakları, Artvin'dekinden farklı olarak, lapa yapılarak yaralara ve çıbanlara karşı kullanılmaktadır (Çakııcıoğlu ve ark. 2007, Deniz ve ark. 2010, Saraç ve ark. 2013). Saraç ve ark. (2013), Chelidonium majus'un çiçekli dallarının egzama, sivilce ve siğil tedavisinde; Arı (2014) bitkinin toprak üstü kısımlarının demlenerek sarılık ve diğer karaciğer hastalıklarına, hemoroide ve ciltte temriye adlı hastalığın tedavisinde kullanıldığını kaydetmişlerdir. Araştırma alanında tespit edilen kullanımı dışında, farklı yörelerdeki çok sayıda araştırmada Hypericum perforatum'dan elde edilen tıbbi yağın ve/veya demlenen çayın ağrıkesici, ateş düşürücü, iştah açıcı, direnç artırıcı, sakinleştirici, ishale karşı, yanık tedavisinde, gastrit ve 
ülser tedavisinde, böbrek, karaciğer, safra ve sinirsel rahatsızlıklara karşı kullanıldığı bildirilmiştir (Çakılcıŏglu ve ark. 2007, Deniz ve ark. 2010, Saraç ve ark. 2013, Arı 2014, Akan ve Bakır Sade 2015, Akbulut 2015).

Tıbbi özelliğe sahip Trifolium sp. ve Achillea sp. gibi bitkilerin ise ya bilinen kullanım amacı dışında ya da tıbbi amaç dışı (şans, uzaklaştırıı) kullanıldığı belirlenmiştir. Artvin'de Achillea millefolium'un yapraklarının yaraların iyileştirilmesinde ve kanamaların durdurulmasında kullanıldığı tespit edilmiştir. Literatürde, adet söktürücü (Ünver 2019), zayıflamak için, idrar yolu iltihabı ve adet sancılarında (Polat ve Satıl 2010), bağırsak ve mide üşütmelerinde, hemoroit, sedef hastalığı, mayasıl ve gece kaçırmalarında (Sarıkan 2007), genel vücut iltihabı, şeker hastalığı ve soğuk algınlığında (Akan ve Bakır Sade 2015) kullanıldığı bildirilmiştir. Trifolium türlerinin ise balgam söktürücü, antiseptik ve yatıştırıcı olarak kullanıldığı kaydedilmiştir (Çakılcıoğlu ve ark. 2007).

Yöre halkının tedavi amacı ile kullandığını bildirdiği bazı karışımlar aşağıda verilmiştir.

Karışım 1. Olea europaea (zeytin) yaprağı, Viscum album (titri) yaprakları ile birlikte kaynatılıp, suyu kolesterol için içilir (Köseler köyü).

Karışım 2.Thymus praecox, Achillea sp. ve Alchemilla sp. bitkileri karıştırılarak kaynatılır ve suyu direnç artırıcı olarak ve soğuk algınlığına karşı içilir (Ortaköy köyü).

Karışım 3. Urtica dioica (ısırgan) tohumları, bal ile karıştırılarak astım ve bronşit için kullanıı (Bağcılar köyü, Kalburlu köyü, Ortaköy köyü).

Karışım 4. Pinus sylvestris (çam) reçinesi zeytinyağı ve balmumu karıştırılarak yaralara sürülür (Balıüzüm köyü).

Yerel halk, daha önce yapılan çalışmalarda olduğu gibi, özellikle toz halindeki bitki parçalarının ve tohumların veya tadı nedeniyle kullanılması güç materyallerin yenilmesini kolaylaştırmak için yardımcı madde olarak bal ve zeytinyağını kullanmayı tercih etmektedir (Saraç ve ark. 2013, Akbulut ve Özkan 2014, Akbulut ve ark. 2019).
Bölge halkının çeşitli amaçlarla kullandığı doğal bitkiler genel olarak değerlendirildiğinde, Taraxacum sp. (Baytop 1999, Bağcl ve ark. 2006, Kurnaz Karagöz 2013, Karakurt 2014, Demir ve ark. 2017), Tragopogon sp. (Savran ve ark. 2008, Karakurt 2014), Falcaria vulgaris (Karagöz Kurnaz 2013), Ferula sp. (Polat ve ark. 2012) gibi taksonların, literatürde çeşitli tıbbi özellikleri nedeniyle kullanıldıkları kayıt altına alınmış olsa da, Artvin halkı tarafından bilinen herhangi bir tıbbi gerekçeye dayandırılmadan yiyerek ya da içilerek tüketildikleri tespit edilmiştir.

En yüksek kullanım değeri (VU), kullanımı en çok bildirilen (52 kişi) Tilia rubra subsp. caucasica (0.38) için hesaplanmıştır. En düşük kullanım değeri ise yalnızca birer kişi tarafından kullanımı bildirilen Achillea millefolium, Diospyros lotus, Rhododendron luteum, Onobrychis cornuta, Trifolium pratense, Euphorbia spp., Rubus spp. için 0.007 olarak hesaplanmıştır. Diğerlerine kıyasla daha yaygın olarak kullanılan bitkiler Plantago (0.24) ve Satureja (0.11) türleri ve Rosa canina (0.10) olarak sıralanabilir (Çizelge 2).

Tıbbi bitkilerin tedavisi için kullanıldığı bildirilen sağlık sorunları 11 ana grup altında toplandı (Çizelge 3). Oluşturulan hastalık grupları içinde sarılık hastalığı için yalnızca 2 farklı kişi aynı bitki (Cyclamen coum) hakkında bilgi vermiştir. Bu hastalık için hesaplanan FIC değeri 1'dir. Ancak, bitki ve hastalık ile ilgili bilgi veren katılımcı sayısı az olduğundan, bitkinin UV (0.01) ve FL (1.45) değerleri düşük çıkmıştır. UV ve FL değerleri bitkilerin tedavi amaçıı kullanımlarının yoğunluğu ve katılımcı sayısıyla orantılıdır. Bitkinin yörede kullanım yoğunluğunu/sıklığını ifade eden FL değeri göz ardı edilemeyecek kadar düşük çıktığından, bitkinin sarılık tedavisinde kabul gördüğünü yalnızca FIC değerine bakarak söylemek doğru olmaz. Hesaplanan FIC değeri yüksek olsa bile Cylamen coum'un sarılık tedavisi için yörede yoğunluklu olarak kullanılan tıbbi bitkiler arasında olmadığı ifade edilebilir. Diğer hastalık grupları için en yüksek ' $F I C$ ' değerleri üst solunum yolu hastalıkları (0.87) ve cilt hastalıkları (0.72) için hesaplandı. Onları üriner sistem hastalıkları $(0.50)$ ve bağırsak hastalıklarının (0.50) izlediği saptandı. En düşük 'FIC' değeri ise mide hastalıkları (0.16) için hesaplandı (Çizelge 3). Bitkilerin kullanımı ile ilgili en fazla bildirim nezle, grip soğuk algınlığı, öksürük, boğaz ağrısı olarak bildirilen üst 
solunum yolu hastalıkları için yapılmıştır. Akciğer hastalıkları (9 kişi) için yapılan bildirim sayısı az görünse de, üst solunum yolu rahatsızlıklarının ( 80 kişi) oluşturulan başlıca hastalık gruplarında ayrı değerlendirildiği dikkate alınmalıdır. Astım, bronşit ve diğer akciğer rahatsızlıkları için verilen bildirimler bu hastalık grubuna dâhil edildiğinde, genel olarak solunum sistemi hastalıklarının (89 kişi-17 bitki) en yüksek bildirime sahip olduğu söylenebilir. En çok bildirim alan ikinci hastalık grubu ise neredeyse tamamının yara, iltihaplı yara ve çıban tedavisi, yalnızca ikisi yanık ve nasır-siğil, olarak belirtilen cilt hastalıkları (40 kişi)'dır. Onları kalp damar hastalıkları, kas ve eklem ağrıları, üriner sistem hastalıkları ve endokrin sistem hastalıkları izler. Kalp damar hastalıkları ve kas-eklem ağrıları için bilgi veren katılımcı sayısı solunum sistemi ve cilt hastalıklarına göre az gibi görünse de, kullanımı bildirilen bitki sayısı hemen hemen onlara eşittir (Çizelge 3). Ayrıca, güneş çarpmasına karşı kullanılan, ağız yarası ve diş ağrısına iyi gelen ve vücut direncini artıran bitkilerde rapor edilmiştir. Ancak, bilgi veren kişi sayısı az (1 kişi) olduğu için çizelgede yer verilmemiştir.

Çizelge 3. Hastalık grupları için Fikir Birliği Faktörü (FIC)

$\begin{array}{lccc}\text { Hastalık grupları } & \begin{array}{c}\text { Bilgi veren } \\ \text { katılımcı sayısı }\end{array} & \begin{array}{c}\text { Kullanılan } \\ \text { bitki sayısı }\end{array} & 12 \\ \text { Kalp damar hastalıkları } & 16 & 7 & 0.27 \\ \text { Endokrin sistem hastalıkları } & 9 & 8 & 0.25 \\ \text { Üriner sistem hastalıkları } & 15 & 6 & 0.50 \\ \text { Akciğer hastalıkları } & 9 & 11 & 0.37 \\ \text { Grip-nezle-soğuk algınlığı } & 80 & 6 & 0.87 \\ \text { Mide hastalıkları } & 7 & 2 & 0.16 \\ \text { Bağırsak hastalıkları } & 3 & 1 & 0.50 \\ \text { Sarılık } & 2 & 12 & 1 \\ \text { Cilt hastalıkları } & 41 & 12 & 0.72 \\ \text { Kas ve eklem ağrıları } & 16 & 3 & 0.27 \\ \text { Kanser } & 4 & & 0.33 \\ \end{array}$

Daha önce yapılan çeşitli çalışmalarda, en yüksek FIC değerinin cilt hastalıkları kategorisinde (0.62; Polat ve ark. 2015) (0.60; Hayta ve ark. 2014) tespit edildiği bildirilmiştir. Bazı çalışmalarda ise romatizmanın en yüksek (0.72), cilt hastalıklarının en düşük (0.27) FIC değerine sahip olduğu belirtilmiştir (Gürdal ve Kültür 2013). Espiye'de yapılan bir çalışmada solunum yolu sorunları için FIC değeri 0.49'dur (Polat ve ark. 2015). Benzer şekilde Edremit'te en yüksek FIC değeri iştahsızlık ve hipertansiyon (0.87) tedavisi için tespit edilirken, solunum sistemi hastalıkları için FIC değeri 0.33 olarak bulunmuştur (Polat ve Satıl 2012). Güzel ve ark. (2015) ise Hatay'da yaptıkları çalışmada en yüksek FIC değerini solunum sistemi hastalıkları (0.93) için hesaplamıştır. FIC için hesaplanan yüksek bir değer, bilgi verenlerin bir hastalık kategorisi için bitki türü kullanımı konusunda hem fikir olduklarını gösterir. Düşük bir değer ise bitkilerin rastgele seçildiğini veya bilgi verenlerin kullanımları hakkında bilgi alışverişinde bulunmadığını göstermektedir (Güzel ve ark. 2015).

Yerel halkın her hastalık kategorisinde en çok kullandı̆̆ı, dolayısıyla en önemli bitkiler ortaya konulmaya çalışımıştır. Hesaplanan en yüksek FIC değerlerine sahip, solunum sistemi hastalıklarında soğuk algınlığı için Tilia rubra ( $\mathrm{FI}=37.68$ ) ve öksürük için Rosa canina ( $\mathrm{Fl}=9.42)$, cilt hastalıklarında ise özellikle yara ve çıban tedavisinde sıkça kullanıldığı belirlenen Plantago türleri (Fl= 18.84) öne çıkmıştır. Kalp damar hastalıkları grubunda kolesterol tedavisinde öne çıkan Viscum album için Fl \% değeri 3.62 olarak hesaplanmıştır. Artvin'de yapılan diğer çalışmada solunum sistemi kategorisinde Tilia rubra ve Rosa canina için \% Fl değeri 100 olarak hesaplanmıştır (Eminağaoğlu ve ark. 2017).

Etnobotanik kültürünün kayıtlı hale getirilmesi bakımından bilimsel nitelikli araştırmalar çok önemlidir. 
Bu çalışma ile Artvin yöresinde bazı tıbbi bitkilerin yöresel kullanımları ortaya konulmaya çalışılmıştır. Başta grip ve nezle olmak üzere solunum sistemi hastalıkları ve cilt hastalıklarında bitkilerle geleneksel tedavi yöntemlerinin kullanıldığı ve bu hastalıkların tıbbi bitkilerle tedavisi konusunda fikir birliğinin yüksek olduğu sonucuna varılmıştır. Endemik olmayan ancak relikt-VU kategorisinde yer alan Osmanthus decorus'un tıbbi kullanımı ilk defa kayıt altına alınmıştır. Endemik veya nadir taksonların kullanımı ve tüketimi ile ilgili halkın bilgilendirilmesine ihtiyaç vardır. Bu tür etnobotanik çalışmalardan elde edilen veriler detaylı biyokimyasal çalışmalara altıık oluşturabilir.

\section{Teşekkür}

Bu çalışma Artvin Çoruh Üniversitesi, Fen Bilimleri Enstitüsü, Orman Botaniği Anabilim dalında yürütülen Yüksek Lisans tezinden üretilmiştir.

\section{KAYNAKLAR}

Abe R, Ohtani K (2013) An ethnobotanical study of medicinal plants and traditional therapies on Batan Island, the Philippines. J. Ethnopharmacol 145: 554-565.

Acıbuca V, Bostan Budak D (2018) Dünya'da ve Türkiye'de Tıbbi ve Aromatik Bitkilerin Yeri ve Önemi, Çukurova Tarım ve Gıda Bilimleri Dergisi 33 (1): 37-44.

Akan H, Bakır Sade Y (2015) Kâhta (Adıyaman) Merkezi ve Narince Köyü'nün Etnobotanik Açıdan Araştırılması. BEÜ Fen Bilimleri Dergisi 4 (2): 219-248.

Akbulut S, Özkan, ZC (2014) Traditional usage of some wild plants in Trabzon region (Turkey). Kast. Uni. J. Forest. Fac. 14 (1): 135-14.

Akbulut S (2015) Differences in the Traditional Use of Wild Plants between Rural and Urban Areas: The Sample of Adana. Studies on Ethno-Medicine 9 (2): 141-150.

Akbulut S, Karaköse M, Özkan ZC (2019) Traditional Uses of Some Wild Plants in Kale and Acıpayam Provinces in Denizli. Kastamonu Üniversitesi, Orman Fakültesi Dergisi 19 (1): 72-81.

Albuquerque UP, Lucena RFP, Montero JM, Florentino ATN and Almeida CF (2006) Evaluating two quantitative ethnobotanical techniques. Ethnobot. Res. App. 4: 51-60.

Alkan G (2019) Kılıçkaya köyü ve çevresinin (Yusufeli-Artvin) halk ilacı olarak kullanılan bitkilerinin belirlenmesi, Yüksek Lisans Tezi, Artvin Çoruh Üniversitesi, Fen Bilimleri Enstitüsü, Artvin.

Austin DF (2004) Florida Ethnobotany, CRC press, USA.

Arı S (2014) Afyonkarahisar ve Civarında Halk Tarafından Kullanılan Bazı Bitkilerin Etnobotanik Özellikleri, Doktora Tezi, Afyon Kocatepe Üniversitesi Fen Bilimleri Enstitüsü, Afyonkarahisar.

Bağcı Y, Erdoğan R, Doğu S (2016) Sarıveliler (Karaman) ve Çevresinde Yetişen Bitkilerin Etnobotanik Özellikleri, Selçuk Üniversitesi, Fen Fakültesi Fen Dergisi 42 (1), 84-107.

Barros FB, Varela SA, Pereira HM, Vicente L (2012) Medicinal use of fauna by a traditional community in the Brazilian Amazonia. Journal of Ethnobiology and Ethnomedicine 8:1-37.
Baykal H (2015) Başhemşin (Çamlıhemşin/Rize)'in Florası, Fitososyolojisi ve Etnobotanik Özellikleri, Doktora Tezi, Recep Tayyip Erdoğan Üniversitesi, Fen Bilimleri Enstitüsü, Rize.

Baytop T (1999) Türkiye'de Bitkiler ile Tedavi Geçmişte ve Bugün, Nobel Tıp Kitabevi, İstanbul.

Çakılcıoğlu U, Türkoğlu İ, Kürşat M, (2007) Harput (Elazığ) ve Çevresinin Etnobotanik Özellikleri. Fırat Üniversitesi Doğu Araştırmaları Dergisi 5 (2): 22-28.

Davis PH (1965-1985) Flora of Turkey and The East Aegean Islands, Vol. 1-9, Edinburgh University Press, Edinburgh.

Davis PH, Mill RR,Tan K (edlr.) (1988) Flora of Turkey and the East Aegean Islands. Vol. 10. Edinburgh University Press, Edinburgh, UK.

Deniz L, Serteser A, Kargıoğlu M (2010) Uşak Üniversitesi ve Yakın Çevresindeki Bazı Bitkilerin Mahalli Adları ve Etnobotanik Özellikleri. Afyon Kocatepe Üniversitesi Fen Bilimleri Dergisi 10 (1): 57-72.

Demir E, Sürmen B, Özer H, Kutbay HG (2017) Salıpazarı ve Çevresinde (Samsun/Türkiye) Doğal Olarak Yetişen Bitkilerin Etnobotanik Özellikleri. Karadeniz Fen Bilimleri Dergisi, 7 (2): 68-78.

Eminağaoğlu Ö, Hacıkamiloğlu İ, Keskin H, Akyıldırım Beğen, H, Aksu G (2015) Artvin'in Doğal Bitkileri. Promat, İstanbul.

Eminağaoğlu Ö, Göktürk T, Akyıldırım Beğen H (2017) Traditional uses of medicinal plants and animals of Hatila Valley National Park, Artvin. Biological Diversity and Conservation 10 (3): 26-35.

Eraydın S (2010) Camili Biyosfer Rezerv Alanının Tıbbi Bitkileri, Yüksek Lisans Tezi, Artvin Çoruh Üniversitesi, Fen Bilimleri Enstitüsü, Artvin.

Ertuğ F (2002) Bodrum Yöresinde Halk Tıbbında Yararlanılan Bitkiler, 14. Bitkisel İlaç Hammaddeleri Toplantısı, Eskişehir, 29-31 Mayıs, 76-93 s.

Faydaoğlu E, Sürücüoğlu MS (2011) Geçmişten Günümüze Tıbbi Ve Aromatik Bitkilerin Kullanılması ve Ekonomik Önemi, Kastamonu Üniversitesi, Orman Fakültesi Dergisi 11(1): 52-67.

Friedman J, Yaniv Z, Dafni A, Palewitch D (1986) A preliminary classification of the healing potential of medicinal plants, based on a rational analysis of an ethnopharmacological field survey among Bedouins in the Negev desert. Israel. Journal of Ethnopharmacology 16: 275-287.

Güner A, Aslan S, Ekim T, Vural M, Babaç MT (edlr.) (2012) Türkiye Bitkileri Listesi (Damarlı Bitkiler), Nezahat Gökyiğit Botanik Bahçesi ve Flora Araştırmaları Derneği Yayını, İstanbul.

Güneş F, Özhatay N (2011) An ethnobotanical study from Kars (Eastern) Turkey. Bio. Di. Con. 4 (1): 30-41.

Güzel Y, Güzelşemme M, Miski M (2015) Ethnobotany of medicinal plants used in Antakya: A multicultural district in Hatay Province of Turkey. J. Ethnopharmacol. 174: 118-152.

Gürdal B, Kültür Ş (2013) An ethnobotanical study of medicinal plants in Marmaris (Mugla, Turkey). J. Ethnopharmacol. 146: 113-126.

Hayta S, Polat R, Selvi S (2014) Traditional uses of medicinal plants in Elazığ (Turkey). J. Ethnopharmacol. 154: 613-623.

Heinrich M, Ankli A, Frei B, Weimann C, Sticher O (1998) Medicinal plants in Mexico: Healers' consensus and cultural importance. Social Science \& Medicine 47: 1859-1871.

Heinrich M, Barnes J, Gibbons S, Williamson EM (2004) Fundamentals of Pharmacognosy and Phytotherapy, Edinburgh, Churchill Livingstone.

Hossain U, Rahman MO (2018) Ethnobotanical uses and informant consensus factor of medicinal plants in Barisal district, Bangladesh. Bangladesh J. Plant Taxon. 25(2): 241-255.

Karaköse M, Akbulut S, Özkan ZC (2019) Ethnobotanical study of medicinal plants in Torul district, Turkey. Bangladesh J. Plant Taxon. 26 (1): 29-37. 
Karakurt E (2014 9 Kelkit (Gümüşhane) İlçesinin Etnobotanik Özellikleri, Yüksek Lisans Tezi, Erzincan Üniversitesi, Fen Bilimleri Enstitüsü, Erzincan.

Kargıŏlu M, Cenkci S, Serteser A, Evliyaoğlu N, Konuk M, Kök MŞ, Bağcı Y (2008) An ethnobotanical survey of Inner-West Anatolia, Turkey. Human Ecolog, 36(5): 763-777.

Koçyiğit M (2005) Yalova İlinde Etnobotanik Bir Araştırma, Yüksek Lisans Tezi, İstanbul Üniversitesi, Sağlık Bilimleri Enstitüsü, İstanbul.

Kurnaz Karagöz F (2013) Suşehri (Sivas) Bölgesinin Etnobotanik Açıdan Değerlendirilmesi, Yüksek Lisans Tezi, Afyon Kocatepe Üniversitesi, Fen Bilimleri Enstitüsü, Afyonkarahisar.

Nacakçı FM, Dutkuner i (2018) A study of ethnobotany in Kumluca (Antalya). Turkish Journal of Forestry 19 (2): 113-119.

Nohutçu L, Tunçtürk M, Tunçtürk R (2019) Yabani Bitkiler ve Sürdürülebilirlik. Yüzüncü Yıl Üniversitesi Fen Bilimleri Enstitüsü Dergisi 24 (2): 142-151.

Polat R, Çakılcıoğlu U, Kaltalioğlu K, Denizhan Ulusan M, Türkmen Z (2015) An ethnobotanical study on medicinal plants in Espiye and its surrounding (Giresun- Turkey), Journal of Ethnopharmacology 163: 1-11.

Polat R, Satıl F (2010) Havran ve Burhaniye'de (Balıkesir) Etnobotanik Araştırmaları. Türkiye Bilimler Akademisi Kültür Envanteri Dergisi 8 (2): 65-100.

Polat R, Selvi S, Çakılcıoğlu U, Açar M (2012) Bingöl semt pazarlarında satılan yabani bitkilerin etnobotanik açıdan incelenmesi. Biological Diversity and Conservation 5(3): 155-161.

Polat R, Satıl F (2012) An ethnobotanical survey of medicinal plants in Edremit Gulf (Balıkesir-Turkey). J. Ethnopharmacol. 139: 626-641.

Saraç DU, Özkan ZC, Akbulut S (2013) Rize İlinin Etnobotanik Özellikleri. Biological Diversity and Conservation 6 (3): 57-66.

Savran A, Bağcı Y, Kargıŏlu M (2008) Gemerek (Sivas) ve Çevresindeki Bazı Bitkilerin Yerel Adları ve Etnobotanik Özellikleri. Afyon Kocatepe Üniversitesi, Fen Bilimleri Dergisi 8 (1): 313-321.

Sarıkan I (2007) Kazdağları Yöresinin Geleneksel İlaçlarının Saptanması, Yüksek Lisans Tezi, Ege Üniversitesi, Sağlık Bilimleri Enstitüsü, İzmir.
Trotter RT, Logan MH (1986) Informant census: A new approach for identifying potentially effective medicinal plants. In: Etkin, L.N. (Ed.), Plants in indigenous medicine and diet. Routledge, Bedford Hill, NY, pp. 91-112.

Ullah S, Khan MR, Shah NA, Shah SA, Majid M, Farooq MA (2014) Ethnomedicinal plant use value in the Lakki Marwat District of Pakistan. Journal of Ethnopharmacology 158: 412-422.

Ünver A (2019) Lamas Çayı Çevresindeki Köylerde (Erdemli, Silifke/Mersin) Etnobotanik Araştırmalar. Yüksek Lisans Tezi, Balıkesir Üniversitesi, Fen Bilimleri Enstitüsü, Balıkesir.

Yeşilada E (2002) Biodiversity in Turkish Folk In: Sener, B. (Ed.), Biodiversity: Biomolecular Aspects of Biodiversity and Innovative Utilization. Kluwer Academic/Plenum Publishers, London.

\section{Ek 1. Anket Soruları}

1. Bilgi verenin yaşı ve cinsiyeti.

2. Bilgi verenin eğitim seviyesi.

3. Bilgi verenin mesleği ve ikamet yeri

4. Bildiğiniz tıbbi bitkiler nelerdir?

5. Tıbbi bitkileri hangi amaçlarla kullanıyorsunuz?

6. Bitkilerin hangi kısımlarını kullanıyorsunuz?

7. Kullanılacak bitkileri nasıl hazırlıyorsunuz?

8. Kullanılan bitkinin yerel adı nedir?

9. Bildiğiniz zehirli bitkiler nelerdir? Onları nasıl kullanıyorsunuz?

10.Bildiğiniz gıda bitkileri nelerdir? Onları nasıl kullanıyorsunuz?

11.Preparatı hazırlarken yardımcı maddeler kullanıyor musunuz? 